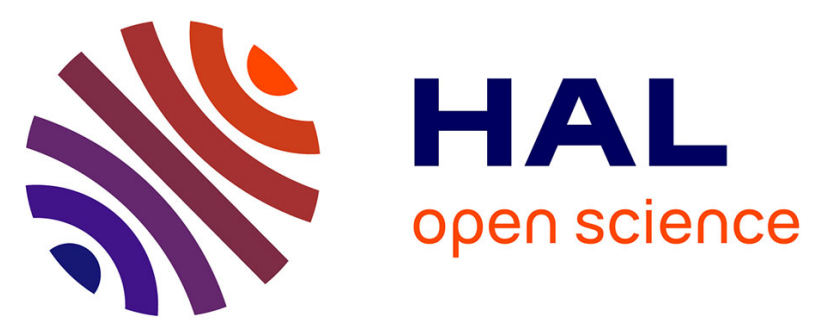

\title{
Rough Design of a Double-Stator Axial Flux Permanent Magnet Generator for a Rim-Driven Marine Current Turbine
}

\author{
Sofiane Djebarri, Jean-Frederic Charpentier, Franck Scuiller, Mohamed \\ Benbouzid, Sylvain Guemard
}

\section{To cite this version:}

Sofiane Djebarri, Jean-Frederic Charpentier, Franck Scuiller, Mohamed Benbouzid, Sylvain Guemard. Rough Design of a Double-Stator Axial Flux Permanent Magnet Generator for a Rim-Driven Marine Current Turbine. Industrial Electronics (ISIE), 2012 IEEE International Symposium on, May 2012, Hangzhou, China. pp.1450-1455, 10.1109/ISIE.2012.6237305 . hal-01073619

\section{HAL Id: hal-01073619 https://hal.science/hal-01073619}

Submitted on 7 May 2015

HAL is a multi-disciplinary open access archive for the deposit and dissemination of scientific research documents, whether they are published or not. The documents may come from teaching and research institutions in France or abroad, or from public or private research centers.
L'archive ouverte pluridisciplinaire HAL, est destinée au dépôt et à la diffusion de documents scientifiques de niveau recherche, publiés ou non, émanant des établissements d'enseignement et de recherche français ou étrangers, des laboratoires publics ou privés. 


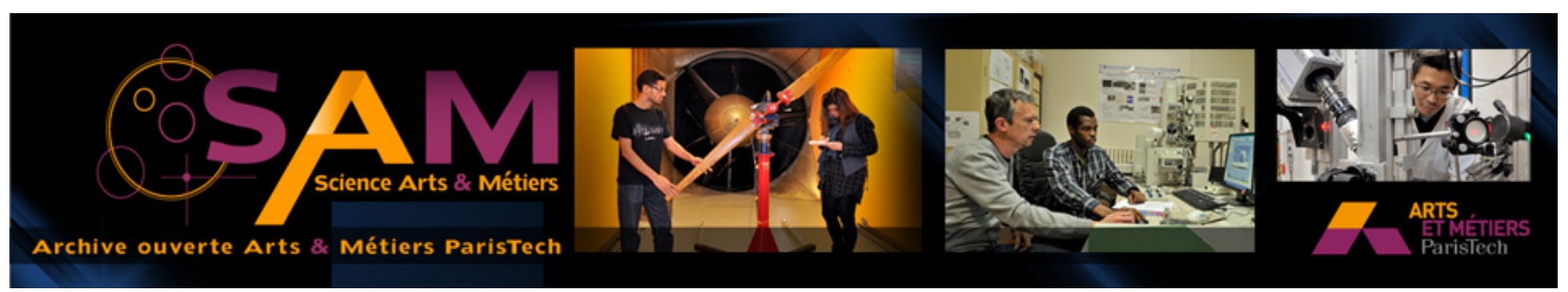

\section{Science Arts \& Métiers (SAM)}

is an open access repository that collects the work of Arts et Métiers ParisTech researchers and makes it freely available over the web where possible.

This is an author-deposited version published in: http://sam.ensam.eu

Handle ID: .http://hdl.handle.net/10985/8714

\section{To cite this version :}

Sofiane DJEBARRI, Jean-Frederic CHARPENTIER, Franck SCUILLER, Mohamed BENBOUZID, Sylvain GUEMARD - Rough Design of a Double-Stator Axial Flux Permanent Magnet Generator for a Rim-Driven Marine Current Turbine - In: Industrial Electronics (ISIE), 2012 IEEE International Symposium on, China, 2012-05 - Industrial Electronics (ISIE), 2012 IEEE International Symposium on -2012 


\title{
Rough Design of a Double-Stator Axial Flux Permanent Magnet Generator for a Rim-Driven Marine Current Turbine
}

\author{
Sofiane Djebarri ${ }^{1}$, Jean Frédéric Charpentier ${ }^{1}$, Franck Scuiller $^{1}$, Mohamed Benbouzid ${ }^{2}$ and Sylvain Guemard ${ }^{3}$ \\ ${ }^{1}$ French Naval Academy, IRENav EA 3634, 29240 Brest Cedex 9, France \\ e-mail: Sofiane.Djebarri@ecole-navale.fr \\ ${ }^{2}$ University of Brest, EA 4325 LBMS, Rue de Kergoat, CS 93837, 29238 Brest Cedex 03, France \\ e-mail: Mohamed.Benbouzid@univ-brest.fr \\ ${ }^{3}$ ECA-EN Company, Bvd Marcel Paul, Saint Herblain, France \\ e-mail: Guemard.s@eca-en.fr
}

\begin{abstract}
This paper deals with the rough design of a Double-Stator Axial Flux Permanent Magnet Machine (DSAFPM) for a rim-driven Marine Current Turbine (MCT). The DSAFPM machine will be compared to a previously developed and realized Radial Flux Permanent Magnet Machine (RFPM); given the same rim-driven MCT specifications. For that purpose, a first-order electromagnetic design model and a thermal one are developed and used to compare active part mass, cost, and thermal behavior of the two machines.

The obtained results show that such a structure of poly-air gap axial flux machine can be more interesting in terms of compactness and thermal behavior for rim-driven marine current turbines.
\end{abstract}

Index Terms-Marine current turbine, rim-driven concept, permanent magnet machine, axial flux machine, electromagnetic model, thermal model.

\section{INTRODUCTION}

Tidal energy is a renewable source of energy which is predictable many years in advance. It constitutes a good alternative to be combined with other renewable sources of energy [1-2]. The predictability of marine currents makes the connection to the electrical grid very easy. There are also other advantages such as low visual exposure, no noise for the public and reduced environment considerations. Nonetheless, some disadvantages must be noted such as conflicts with other users of the sea and the need for a salt and water proof technologies due to sea immersion [2-4].

The energy conversion of marine current is quite similar in principle to wind energy. Kinetic energy from marine currents is harnessed using similar systems to those developed to extract wind energy [3]. This is particularly the case of the first developed MCTs [2]. However, because of tides low speed and to avoid blades cavitation, the turbine rotational speed is typically below $100 \mathrm{rpm}$.

For conventional generators, the rated speed is very high and the use of a multistage gearbox is needed. This decreases the drive train efficiency and increases maintenance requirements. To make the tidal current energy conversion economically interesting, the MCT will need to have an approximately 30 year's lifespan with maintenance inspections every 5 years [5]. Therefore, MCTs should be highly efficient and reliable.

Hence, for the electric machine side, direct-drive permanent magnet generators appear as the solution that fulfills these requirements especially in terms of reduced maintenance. In direct-drive current turbine systems the electrical generator is directly connected to the turbine. Thus, a direct-drive turbine is operated at low speed and the gearbox is eliminated [6]. Consequently, the maintenance requirements are significantly reduced and the efficiency of the drive train is improved. However, the generator active parts mass and cost are expected to be higher if compared with more conventional generators including gearbox.

Regarding MCTs design, a rim-driven topology seems more favorable than a POD one in so far as the electrical machine volume does not disturb the water flow. Furthermore, rim-driven turbines naturally imply direct-drive generators. In [7], rim-driven and POD direct drive-radial permanent magnet machines are designed for the same MCT specifications. According to this study, the rim-driven topology yields a reduction of about $15 \%$ of the cost of active parts. It must be underlined that the design of such a machine is quite unusual as the active parts are located at the blades periphery (Fig. 1). A rim-driven MCT prototype using a RFPM machine has been designed and tested in our lab [8]. This experimental setup is shown in Fig. 2.

This paper aims to assess the potential of an axial flux PM machine for rim-driven MCTs. Many testing or ongoing projects on marine currents turbines involve axial flux machines technology.

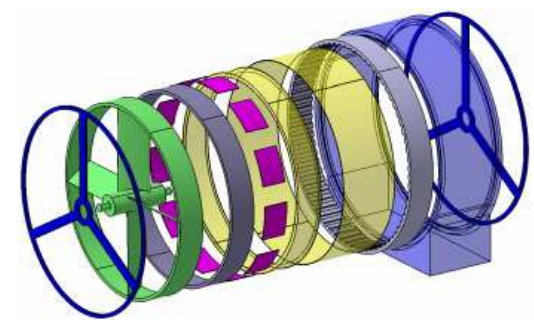

Fig.1. Rim-driven concept with a radial permanent magnet machine. 


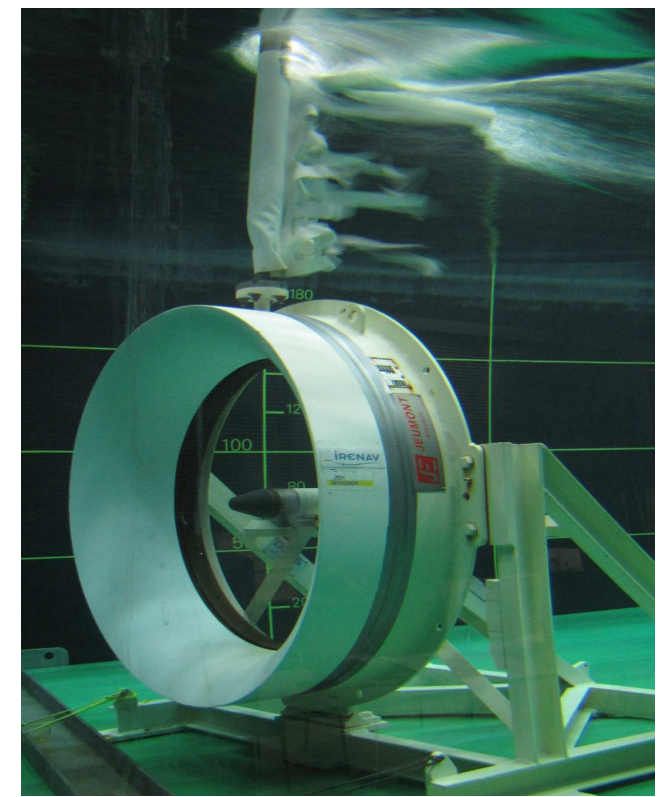

Fig.2. Rim-driven prototype integrating a RFPM machine [8].

One can cite a contra-rotating tidal turbine (CoRMat), developed at the University of Strathclyde (UK), as an example of axial flux PM generators used for an MCT [9]. In comparison with radial flux machines, axial flux machines enable a better compactness, a better efficiency [10] and a high-speed ability [11]. But the high electromagnetic axial force between stator and rotor generates a mechanical stress that can make the design particularly difficult. In order to reduce this mechanical constraint, double-sided PM machines with slotless stator [3], double stator or multi stator can be foreseen. In addition, a DSAFPM machine is more reliable as, if a fault occurs on one of the stators, the generator can operate at half the rated power. That is why we focus on the design of a DSAFPM machine for a rim-driven MCT.

In this paper, the case study is first introduced: the design specifications of an experimental MCT are given. They are used for the DSAFPM machine design. It should be noted that the same specifications have been used to design a RFPM machine rim-driven MCT [7]. The second part of the paper describes the electromagnetic analytical model used to design the DSAFPM machine. In the third part, a thermal model is presented and will be associated to the electromagnetic model. In the last part, the designed DSAFPM machine is compared with the previously designed RFPM machine [7].

\section{DESCRIPTIONS OF THE ADOPTED SPECIFICATIONS}

Located in the north Devon coast of England since 2003 [12-13], the Seaflow turbine has $300 \mathrm{~kW}$ rated power. The $11 \mathrm{~m}$ diameter turbine rotates at $15 \mathrm{rpm}$ for a $2.5 \mathrm{~m} / \mathrm{sec}$ tidal current. In [7], Seaflow turbine specifications are considered to design a rim-driven radial flux PM machine. Table 1 gives the input parameters. In order to make a clear comparison between the RFPM machine and the DSAFPM one, Table 1 parameters remain constant.
TABLE 1

COMMON DiMENSIONS SET BY THE DESIGN SPECIFICATIONS

\begin{tabular}{|c|c|c|c|}
\hline Rotor inner radius (Seaflow) & $R_{0}$ & 5.5 & $\mathrm{~m}$ \\
\hline Torque transmitted by the turbine & $Q$ & 191 & $\mathrm{kNm}$ \\
\hline Turbine speed & $N$ & 15 & rpm \\
\hline Air gap & $Z_{g}$ & 10 & $\mathrm{~mm}$ \\
\hline Winding coefficient & $k_{b 1}$ & 1 & \\
\hline Electrical angle & $\psi$ & 0 & $\mathrm{rad}$ \\
\hline Number of phases & $m$ & 3 & \\
\hline Magnet coercive field & $H_{c}$ & $-10^{6}$ & $\mathrm{~A} / \mathrm{m}$ \\
\hline Maximum air gap flux density & $B_{g \max }$ & 0.4 & $\mathrm{~T}$ \\
\hline Magnet remanent flux density & $B_{r}$ & 1.2 & $\mathrm{~T}$ \\
\hline $\begin{array}{l}\text { Maximum magnetic flux density } \\
\text { in the teeth iron }\end{array}$ & $B_{\text {tmax }}$ & 1.4 & $\mathrm{~T}$ \\
\hline $\begin{array}{l}\text { Maximum magnetic flux density in the } \\
\text { stator yoke iron }\end{array}$ & $B_{Y \max }$ & 1.4 & $\mathrm{~T}$ \\
\hline Slot fill factor & $k_{f}$ & 0.65 & \\
\hline Machine electrical frequency & $f_{\text {mach }}$ & 50 & $\mathrm{~Hz}$ \\
\hline Electrical load in each stator & $A_{L} / 2$ & 51183 & $\begin{array}{c}\mathrm{A} / \mathrm{m} \\
(\mathrm{rms})\end{array}$ \\
\hline Copper current density & $J$ & 7.15 & $\begin{array}{r}\mathrm{A} / \mathrm{mm}^{2} \\
(\mathrm{rms})\end{array}$ \\
\hline Magnet to pole width ratio & $B_{m}$ & 0.65 & \\
\hline Conductors maximum temperature & $T_{\max }$ & 100 & ${ }^{\circ} \mathrm{C}$ \\
\hline Sea water temperature & $T_{\text {water }}$ & 30 & ${ }^{\circ} \mathrm{C}$ \\
\hline
\end{tabular}

For a rim-driven device, the blade geometrical characteristics impose the internal radius, the mechanical torque and the rated speed of the electrical machine. If the mechanical and viscous losses are neglected, the electromagnetic torque $\left\langle T_{E M}\right\rangle$ is equal to the turbine mechanical torque $Q$.

$$
\left\langle T_{E M}\right\rangle=Q
$$

\section{DESCRIPTION AND MODELING OF THE DSAFPM MACHINE}

As shown in Fig. 3, the DSAFPM machine stators consist of two discs that bear the windings. The ironless rotor is directly linked to the turbine blades. In order to separate the active parts of the machine from the sea water, the ironless permanent magnet rotor and the stator slots are covered by an epoxy resin and the stators are located in a hull.

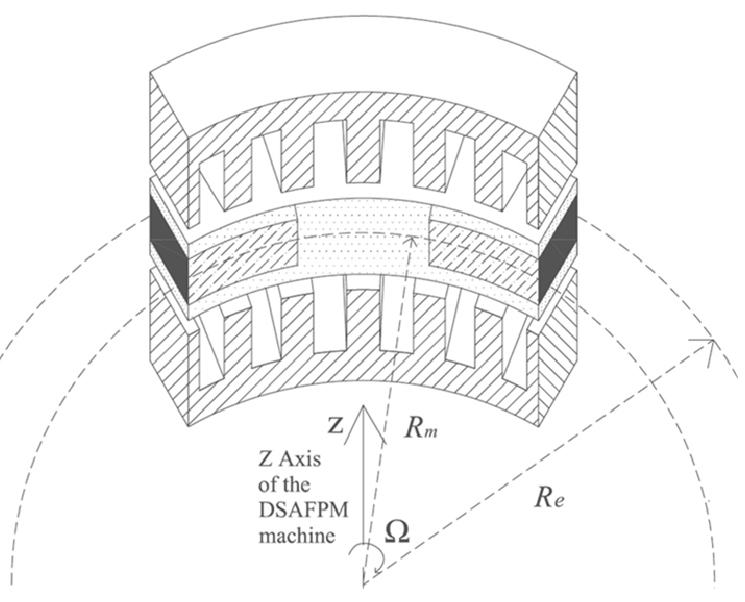

Fig.3. 3D sketch of the DSAFPM machine for two pole pitches. 
The geometry of an axial machine is intrinsically $3 \mathrm{D}$, which makes the modeling more complex. The considered DSAFPM machine is assumed to electromagnetically behave as the corresponding linear machine illustrated in Fig. 4 as a simplification at mean radius of the geometry shown in Fig. 3. This simplification can be admitted because the inner radius imposed by the turbine specifications is very large, $R_{0}=5.5 \mathrm{~m}$ (Table I). For rough design purpose, it is assumed that radius curvature and flux leakages are neglected.

Figure 4 describes the geometry of the equivalent linear machine whose different geometrical parameters are given by Table 2. $\Delta R_{s}$ is the rim radial length that sets permanent magnets on the periphery of the blades. $R_{e}, R_{i}, \beta_{\mathrm{t}}, \beta_{m}, p$ are respectively outer and inner radii, teeth pitch ratio, magnet pole pitch ratio and number of pole pairs.

The machine is supposed to be supplied with sinusoidal currents. The electromagnetic torque can then be estimated by

$$
\left\langle T_{E M}\right\rangle=8 \sqrt{2} A_{L} k_{b 1} B_{\mathrm{g}_{\max }} R_{m}^{2} \Delta R \sin \left(\frac{\beta_{m} \pi}{2}\right) \cos \psi
$$

Where $B_{\text {gmax }}$ is the maximum air gap flux density.

It is then obvious that the maximum torque for given Joule losses is obtained by controlling $\psi$ to zero.

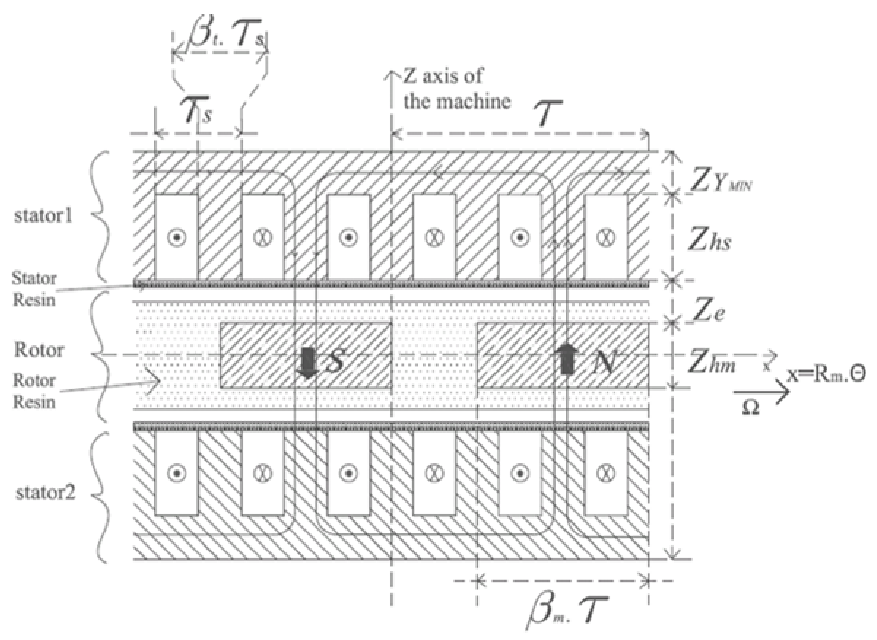

Fig. 4. 2D section of the DSAFPM machine on one pole pairs at the mean radius.

TABLE 2

GEOMETRY PARAMETERS

\begin{tabular}{|c|c|}
\hline Inner radius & $R_{i}=R_{0}+\Delta R_{s}$ \\
\hline Radial length & $\Delta R=R_{e}-R_{i}$ \\
\hline Mean radius & $R_{m}=\left(R_{i}+R_{e}\right) / 2$ \\
\hline Pole pitch ratio & $\tau_{p}=\pi / p$ \\
\hline Poles width & $\tau=\tau_{p} R_{m}$ \\
\hline Slot pitch width & $\tau_{s}=\pi R_{m} /\left(S_{p p} m p\right)$ \\
\hline Slot number per pole and per phase & $\left(1-\beta_{p}\right) \tau_{s}$ \\
\hline Slot opening & $\beta_{m} \tau$ \\
\hline Magnet pole width & \\
\hline
\end{tabular}

This control will be adopted for the rated point.

The magnet height that creates the flux density $B_{\text {gmax }}$ in the air gap is calculated as follows

$Z_{h m}=2 \frac{\left(Z_{g}+Z_{g^{\prime}}\right) B_{g_{\max }}}{\left(B_{r}-B_{g_{\max }}\right)}$

In (3), $Z g$ is the magnetic air gap (the distance between magnets and teeth shoe), $B_{r}$ is the magnet magnetization, $\mathrm{Z}_{g}$, is an additional air gap introduced to take into account slotting effects. For large air gap machines, as is the case of the designed one for rim-driven specifications, $Z_{g}$, is given by [14]

$Z_{g^{\prime}}=\frac{\tau_{s}}{2 \pi}\left[\beta_{t} \ln \left(\beta_{t}\right)+\left(2-\beta_{t}\right) \ln \left(2-\beta_{t}\right)\right]$

where $\beta_{t}$ is the teeth pitch ratio. In addition, the pole pair number is chosen by considering the iron rating frequency $f_{\text {mach }}$ and the rated mechanical speed $\Omega$ of the turbine.

$p_{\max }=\frac{2 \pi f_{\text {mach }}}{\Omega}$

To avoid saturation in the teeth and in the stator yoke, it is considered a maximum value of the flux density in the soft magnetic materials $B_{\text {tmax }}$. Considering the worst case where the tooth is located in front of the location of the maximum flux density in the air gap $B_{\text {gmax }}$, the minimum teeth width can be estimated as

$\beta_{t_{\min }}=\frac{B_{g_{\max }}}{B_{t_{\max }}}$

To avoid saturation in the stator yoke, it is considered a maximum value of the flux density $B_{\text {ymax }}$ in the soft material constituting the stators yoke. Then, the minimum yoke thickness $Z_{Y \min }$ to ensure non saturation is deduced from

$Z_{Y_{\min }}=\beta_{m} \frac{\pi R_{m}}{2 p} \frac{B_{g_{\max }}}{B_{Y_{\max }}}$

Considering an electrical current load $A_{L}$ (rms value) and a current density in the copper $J$ (rms value), the slots minimum depth $Z_{h s}$ can be deduced as

$$
Z_{h s}=\frac{A_{L}}{k_{f} J\left(1-\beta_{t}\right)}
$$

\section{THERMAL MODELING OF THE DSAFPM MACHINE}

Lumped parameters modeling is chosen to study the steady-state thermal behavior of the DSAFM stator part. This model is similar to the model used in [7]. This approach allows us to make a realistic comparison of radial and axial 
structures for this application. The copper and iron losses are considered as heat sources in the network. These heat fluxes cross the different materials constituting the stator and are dissipated in the external environment. Figure 5 shows a sketch of a tooth pitch and the considered heat fluxes.

As in [7], only the conduction and convection heat transfers are considered. The heat flow is assumed to be fully dissipated in the external sea water area and the immersed air gap area in each side of the stators. Heat transfers between slots and teeth are taken into account. In our case, radial heat transfers and end windings heat transfer losses are not taken into account. With this hypothesis the thermal model is pessimistic. So the calculated temperatures will probably be higher than the real ones. In order to establish the thermal network model, let us consider cases which are associated with each part of the tooth pitch stator.

It is considered firstly the case of an elementary material volume as shown in Fig. 6a. This case corresponds for example to the stator cores and slots. This volume has an axial length $l$, an internal radius $R i$, and an external radius $R e$. The material has a thermal conductivity $\lambda$, and the volume is associated with an internal heat power $P$. The corresponding thermal network is given by Fig. $6 \mathrm{~b}$. These considerations allow heat transfer modeling in the axial direction.

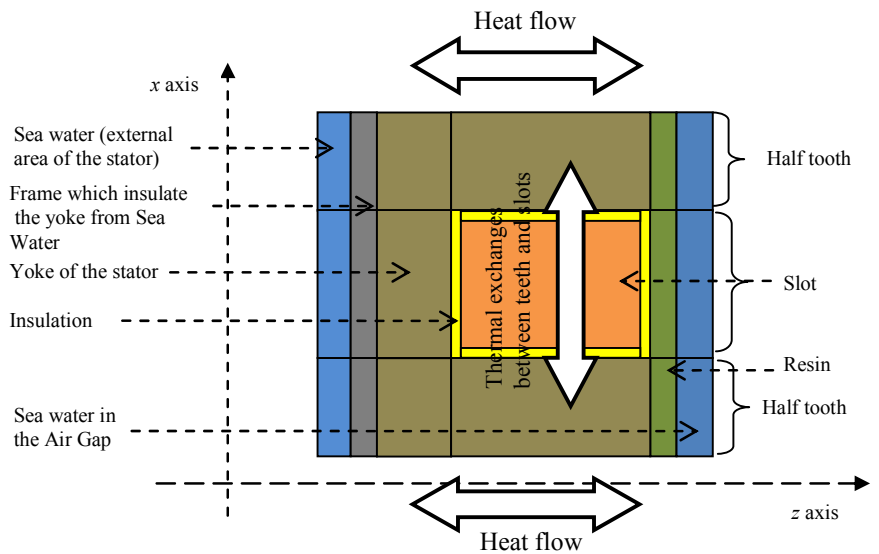

Fig. 5. Considered materials and heat fluxes in the thermal model.

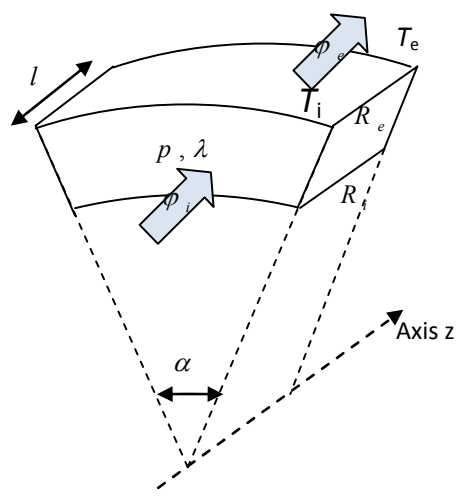

(a)

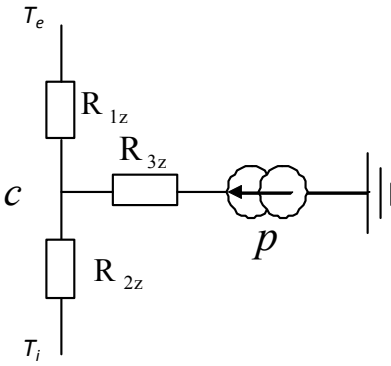

(b)
Fig. 6. (a) Representation of heat exchanges in the axial direction in a portion of material and (b) modeling.
Thermal resistances for Fig. 6 configuration are given by [15].

$\left\{\begin{array}{l}R_{1 z}=\frac{l}{\lambda \alpha\left(R_{e}^{2}-R_{i}^{2}\right)} \\ R_{2 z}=\frac{l}{\lambda \alpha\left(R_{e}^{2}-R_{i}^{2}\right)} \\ R_{3 z}=\frac{l}{3 \lambda \alpha\left(R_{e}^{2}-R_{i}^{2}\right)}\end{array}\right.$

For heat transfer calculation in the orthoradial direction, parallelepiped materials volumes are considered. These volumes are associated with a length $l_{x}$ (in the heat flow direction), a conduction section $S_{c}$, and a thermal conductivity $\lambda$. The corresponding thermal resistance can then be expressed as

$R_{\text {cond }}=\frac{l_{x}}{\lambda S_{c}}$

For all the dissipation surfaces (each lateral face of the stators), a convection coefficient $h_{\text {conv }}$ and a convective area $S$ are considered. The convection thermal resistance is then given by

$R_{\text {conv }}=\frac{1}{h_{\text {conv }} S}$

For heat sources calculation, both copper losses and iron losses in teeth and yoke are considered. For an electrical resistivity $\rho_{C u}$ of the copper, the copper losses in each slot can be calculated as a function of the copper volume $V_{C u}$ and the current density in the copper $J$.

$$
P_{J}=\rho_{\mathrm{Cu}} V_{C u} J^{2}
$$

The iron losses $\mathrm{P}_{F e}(\mathrm{~W} / \mathrm{kg})$ in teeth and yoke are calculated by the following common relationship (that can be found in any manufacturer data sheets).

$$
P_{F e}=P_{F e 0}\left(\frac{f}{f_{0}}\right)^{b}\left(\frac{B_{F e}}{B_{F e}}\right)^{c}
$$

Where $f$ and $B_{F e}$ are respectively the electrical frequency and the iron flux density. As in [7], the values of $b$ and $c$ are set at 1.5 and 2.2 respectively, using FeSi laminated iron sheet.

The convection coefficient with sea water in the external face of the stator is calculated by assuming the flow perpendicular to a cylinder of diameter $D_{c}$, as illustrated in Fig. 7 [16]. This diameter corresponds to a cylindrical-shape nozzle in which the active parts of the machine are inserted. 
[17], which study a case close to the air gap geometry, is used to estimate the Nusselt number in the gap. The convection coefficient is then calculated.

\section{DSAFPM MACHINE DESIGN RESUlTS AND Discussion}

Considering Table 1 and 2 data, the analytical model described in Section III allows determining a single set of the DSAFPM machine geometrical parameters. These main geometrical parameters are given in Table 3 and are illustrated in Fig. 8. As can be observed, the obtained DSAFPM machine is relatively short and thin, which complies with the requirements of a rim-driven MCT. This particular geometry facilitates the insertion of the active parts of the electrical machine in a nozzle surrounding the blades. It can be noticed that these dimensions are comparable to those of the radial PM machine (RFPM) [7].

In order to validate our approach, 3D Finite Element (FE) calculations have been performed using Maxwell-3D ${ }^{\circledR}$. The difference between the electromagnetic torque calculated by the FE method and the required torque (set by common specifications of Table 1) is about $25 \%$. In this kind of rimdriven structure a large magnetic gap, a small pole pitch, and a small radial length lead to a high level of flux leakages (radial and orthoradial). These leakages are not taken into account in the basic analytical model described in Section III. FE calculations show also that the calculated axial machine is not saturated.

Table 4 gives the active part material prices [7]. This data are then used to evaluate the DSAFPM machine active part costs and compare them to the reference RFPM one. Both machines active part costs and masses are given by Figs. 9 and 10. In this study the end-windings geometry is considered as a $\tau$ diameter half-circle, as it is assumed for previously studied RFPM machine [7].

TABLE 3

MAIN DIMENSIONS OF THE RFPM AND DSAFPM MACHINES

\begin{tabular}{|c|c|c|}
\hline & RFPM (sized in [7]) & DSAFPM \\
\hline Pole pair number & 200 & 200 \\
\hline Inner radius (m) & 5.5 & 5.5 \\
\hline Outer radius (m) & 5.6 & 5.5159 \\
\hline Length (cm) & 4 & 3.18 \\
\hline Magnet thickness (cm) & 1 & 1.26 \\
\hline
\end{tabular}

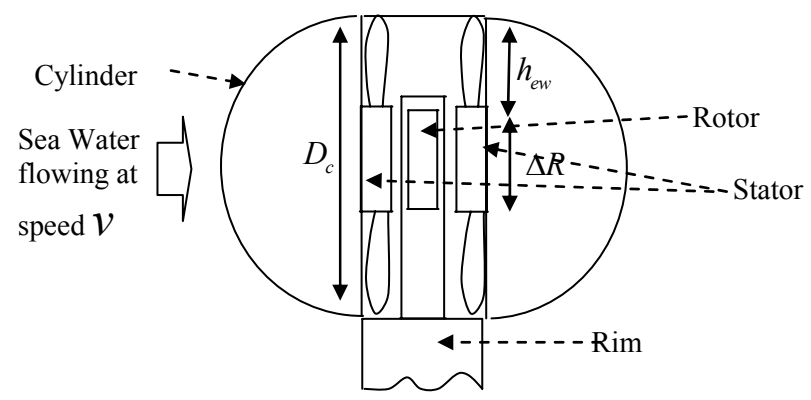

Fig. 7. Representation of a stator inserted in a cylindrical nozzle.

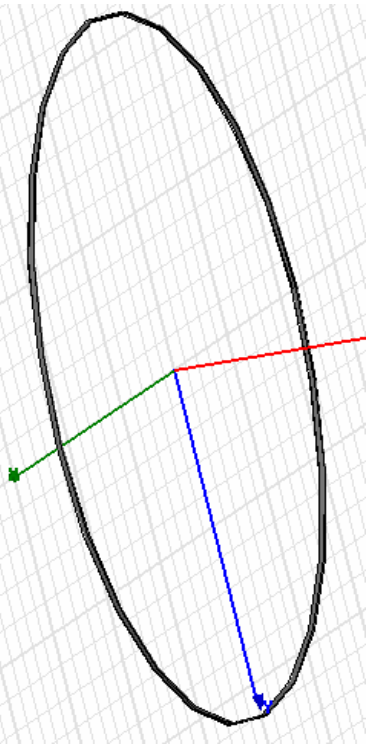

(a)

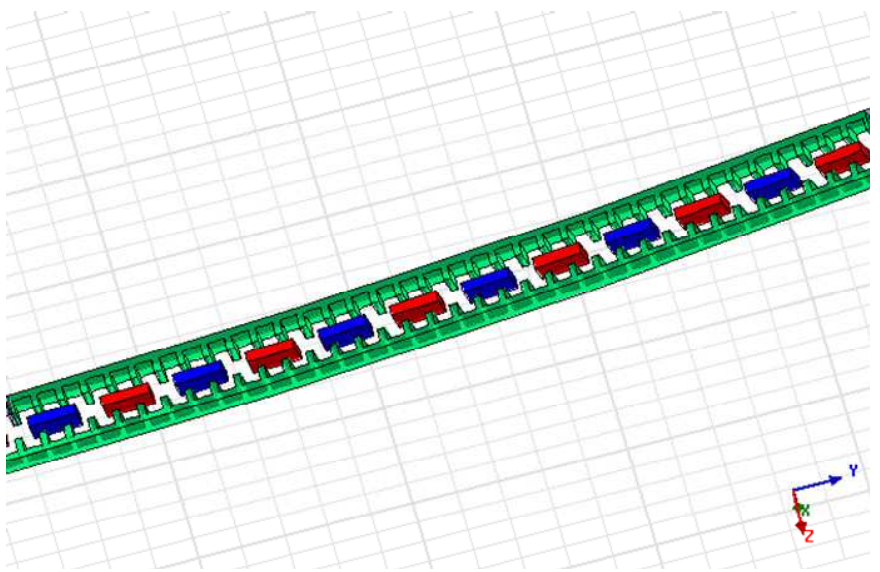

(b)

Fig. 8. (a) Representation of the sized DSAFPM machine active part volumes and (b) zoom on an arc of the machine.

TABLE 4

PRICE OF THE ACTIVE PARTS [7]

\begin{tabular}{|c|c|c|}
\hline Copper & 6.0 & $€ / \mathrm{kg}$ \\
\hline Iron & 0.5 & $€ / \mathrm{kg}$ \\
\hline $\mathrm{NdFeB}$ & 87.0 & $€ / \mathrm{kg}$ \\
\hline
\end{tabular}

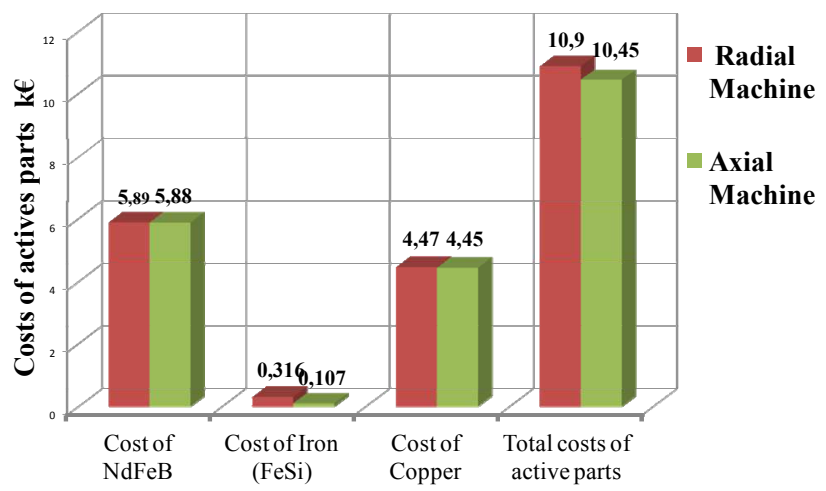

Fig. 9. DSAFPM and RFPM machines active part costs comparison. 


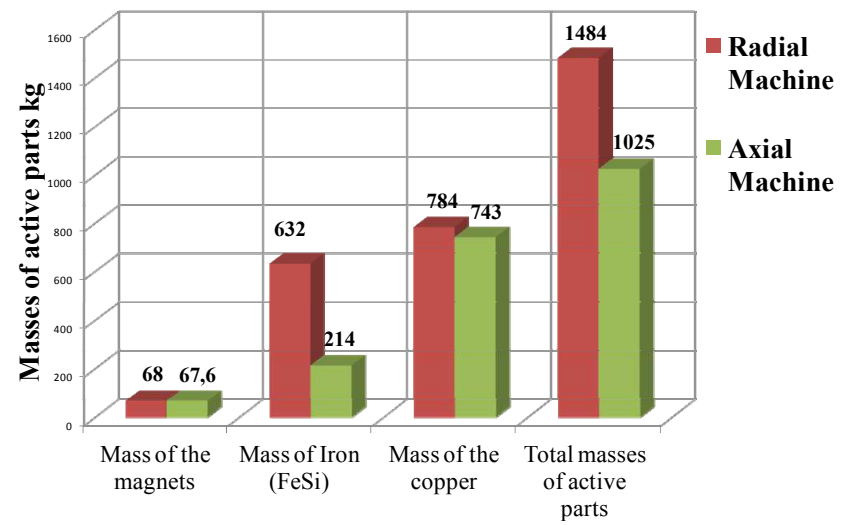

Fig. 10. DSAFPM and RFPM machines active part masses comparison.

From the above obtained results, it appears that the calculated DSAFPM machine is comparable to the radial machine calculated in [7], in terms of volume and cost of active parts (Figs. 9 and 10). This is not surprising because the air gap global electrical load and flux density values are similar for the both designs. Indeed, these common electromagnetic quantities lead to a similar magnetic gap volume. This air gap volume leads therefore to comparable volumes and costs for active materials. It should be noted that the ironless rotor in the DSAFPM machine is lighter in terms of mass than the rotor of the RFPM machine. The rotor turbine inertia is then reduced, which can improve the MCT dynamic performances. As for the radial machine, a significant part of the copper is used in the end windings.

Regarding the thermal behavior of the DSAFPM machine, the maximum estimated temperature in the conductors is only $63^{\circ} \mathrm{C}$. It is about $97^{\circ} \mathrm{C}$ in the corresponding RFPM machine. This result confirms that the DSAFPM machine is thermally more interesting. Moreover, it should be mentioned that this DSAFPM machine first design is not optimized in terms of thermal behavior.

It is then obvious that taking into account thermal constraints should result in a double stator axial machine significantly more compact and less expensive than a radial one for the same specifications.

\section{CONCLUSION}

This paper dealt with the rough design of a DSAFPM machine for a rim-driven MCT. The DSAFPM machine has been compared to a previously developed and realized RFPM machine; given the same rim-driven MCT specifications. For that purpose, a first-order electromagnetic design model and a thermal one have been developed.

Even if, in this first basic design, the two structures volume and cost are quite similar, the obtained results show that the double stator axial machine is less constrained in terms of thermal behavior than the radial machine. Hence it seems possible to achieve better performance in terms of compactness and cost for an MCT application.
However, it is necessary to take into account thermal and power electronics constraints in a global optimization process to confirm the DSAFPM machine advantages in further works.

\section{REFERENCES}

[1] M. Leijon, H. Bernhoff, M. Berg, and O. Agren, "Economical considerations of renewable electric energy production - especially development of wave energy", Renewable Energy, vol. 28, n8, pp. 1201-1209, 2003.

[2] S. Benelghali, M.E.H. Benbouzid and J.F. Charpentier, "Marine tidal current electric power generation technology: State of the art and current status," in Proceedings of the 2007 IEEE IEMDC, Antalya (Turkey), vol. 2, pp. 1407-1412, May 2007.

[3] S. Moury and M.T. Iqbal, "A permanent magnet generator with PCB stator for low speed marine current applications," in Proceedings of the 2009 IEEE ICDRET, Dakha (Bangladesh), pp. 1-4, December 2009.

[4] O. Keysan, A.S. McDonald and M. Mueller, "A direct drive permanent magnet generator design for a tidal current turbine (SeaGen)," in Proceedings of the 2011 IEEE IEMDC, Niagara Falls (Canada), pp. 224229, May 2011.

[5] R.E. Harris, L. Johanning and J. Wolfram, "Mooring systems for wave energy converters: A review of design issues and choices," in Proceedings of the 2004 MAREC, Blyth, (UKA), pp. 1-10, July 2004.

[6] R.S. Semken, M. Polikarpova, P. Roytta, J. Alexandrova, J. Pyrhonen, J. Nerg, A. Mikkola and J. Backman, "Direct-drive permanent magnet generators for high-power wind turbines: Benefits and limiting factors," IET Renewable Power Generation, vol. 6, n¹, pp. 1-8, January 2012.

[7] L. Drouen, J.F. Charpentier, E. Semail, S. Clenet, "Investigation on the performances of the electrical generator of a rim-driven marine current turbine," in Proceedings of the 2008 ICOE, Brest (France), pp. 1-6, October 2008.

[8] L. Drouen, "Machines électriques intégrées à des hélices marines, contribution à une modélisation et conception multi-physique," $P h D$ Thesis, Arts \& Métiers ParisTech, December 2010.

[9] J. Clarke, G. Connor, A. Grant, C. Johnstone and S. Ordonez-Sanchez, "Analysis of a single point tensioned mooring system for station keeping of a contra-rotating marine current turbine," IET Renewable Power Generation, vol. 4, n 6 , pp. 473-487, November 2010.

[10] B.J. Chalmers, W. Wu and E. Spooner, "An axial-flux permanentmagnet generator for a gearless wind energy system," IEEE Transaction on Energy Conversion, vol. 14, n², pp. 251-257, June 1999.

[11] M.R. Dubois, H. Polinder and J.A. Ferreira, "Comparison of generator topologies for direct-drive wind turbines," in Proceedings of the 2000 NORPIE, Aalborg (Denmark), pp. 22-26, June 2000.

[12] Seaflow, "Pilot project for the exploitation of marine currents," $E U$ Research Report, EUR 21616, 2005.

[13] www.marineturbines.com/6/background/14/seaflow/ (last accessed December, 2011).

[14] E. Matagne, Physique Interne des Convertisseurs Electromagnétiques, Milieux Magnétiques Composites. Lecture Notes, UCL, Belgium, www.lei.ucl.ac.be/ matagne/ELEC2311/SEM04/S04P12B.HTM, (last accessed December, 2011).

[15] P.H. Mellor, D. Roberts and D.R. Turner, "Lumped parameter thermal model for electrical machines of TEFC design," IEE Proc. B, vol. 138, $\mathrm{n}^{\circ} 5$, pp. 205-218, September 1991.

[16] J. Huetz and J.P. Petit, Notions de Transfert Thermique par Convection. Technique de l'Ingénieur, Traité de Génie Energétique, A 1540 (in French).

[17] A. Andreozzi, N. Bianco, O Manca and V. Naso, "Effect of a moving plate on heat transfer in a uniform heat flux vertical channel," International Journal of Heat Transfer, vol. 51, n¹5-16, pp. 3906-3912, 2008 . 